\title{
Improving nutritional management within high-risk groups
}

Caroline AM van Wayenburg, Jaap J van Binsbergen, Manon GA van den Berg, Matthias AW Merkx, Wija A van Staveren, Ellen Rasmussen-Conrad and Chris van Weel

\begin{abstract}
The current pitfalls and future possibilities of nutritional management are discussed by two patients with tongue cancer who have suffered from substantial weight loss. Their nutritional problems are illustrative of those among other (cancer) patient groups. The main concerns are the lack of early case finding and dietary treatment, and insufficient nutritional information transfer through referral letters. The GP as a central and longitudinal caretaker faces challenges in improving nutritional management.

Keywords

cachexia; chronic disease; family practice; neoplasms; weight loss
\end{abstract}

\section{INTRODUCTION}

GPs care for many patients at risk for cachexia, in particular those with cancer, chronic obstructive pulmonary disease (COPD), and chronic heart failure. ${ }^{1}$ Cachexia is a complex syndrome that combines anorexia, weight loss, and muscle and adipose tissue decline with weakness. Physicians often recognise cachexia only in the later stages and see it as an inevitable consequence of the disease. However, according to literature, cachexia should already be considered in case of unintentional weight loss of more than $5 \%$ within 6 months, ${ }^{2}$ especially since there is evidence that intervention can stabilise cachexia and improve quality of life. These interventions concern early individualised nutritional support with or without metabolic interference therapy. ${ }^{3,4}$ Nevertheless, the cancer stage generally forms the major determinant of a low quality of life. ${ }^{5}$ Bio-impedence analysis or blood tests (for example, C-reactive protein and albumin levels) are some (additional) possibilities in diagnosing cachexia. ${ }^{1,6}$

The aim of this paper is to illustrate the need for early management of cachexia and the barriers to doing so. Two case histories are presented, identified in a longitudinal observational study on weight loss in patients with head and neck cancer (CAM Van Wayenburg et al, unpublished data, 2008). ${ }^{7}$

nutrition and general practice; $C$ van Weel, professor of general practice, Department of Primary Care; MGA van den Berg, Bc; EL Rasmussen-Conrad, Ir, Department of Dietetics; MAW Merkx, professor of head and neck oncology and oral medicine, Department of Oral Maxillofacial Surgery, Radboud University Nijmegen Medical Centre, Nijmegen, Netherlands. WA van Staveren, professor in nutrition and gerontology, Division of Human Nutrition, University of Wageningen, Wageningen, Netherlands.

\section{Address for correspondence}

Caroline van Wayenburg, Radboud University Nijmegen Medical Centre, Department of Primary Care, PO Box 9101 Internal postal code HAG 117, Nijmegen, $6500 \mathrm{HB}$, Netherlands. E-mail: c.vanwayenburg@hag.umcn.nl

Submitted: 23 October 2008; Editor's response: 11 December 2008; final acceptance: 16 January 2009. (c)British Journal of General Practice 2009; 59: 595-596. DOI: 10.3399/bjgp09X453819

\section{CASE HISTORIES}

The first patient was 61 years old when she visited her GP for a check-up of a painful spot on the tongue. The GP reported an ulcerative spot with a palpable lymph node in the neck. His hypothesis was an infection, or possible malignancy. After 1 week of antibiotic treatment, he referred her to the local hospital. Her medical history included irritable bowel syndrome, anxiety, and hypertension. The local specialist sent her to the head and neck oncology centre for specialised treatment. At the first visit to the centre she had a stable weight $(60$ $\mathrm{kg}$, height $1.58 \mathrm{~m}$ [body mass index $\{\mathrm{BMI}\} 24.0$ $\left.\mathrm{kg} / \mathrm{m}^{2}\right]$ ) and received curative surgical treatment (tumour stage T1N1M0). She remained in good nutritional health during care at the head and neck 


\section{How this fits in}

GPs provide care to many patient groups at high-risk for weight loss, such as those with cancer, chronic obstructive pulmonary disease, and chronic heart failure. Regular measurements of their body weight is essential for early intervention that may contribute to patients' quality of life. oncology centre. In the following year, she suffered from a throat infection for which the GP treated her with antibiotics. According to the study's 3-monthly weight measurements, the patient lost $4.2 \mathrm{~kg}(6.7 \%)$ within 3 months, which the GP's record suggested was due to anorexia and nausea resulting from the infection and antibiotic side-effects, as well as difficulties with her 'new' diet for recently diagnosed coeliac disease. No intervention had been undertaken.

The second patient was 83 years old, suffering from ulcerative colitis, depression, and aortic stenosis. Her symptoms were persistent throat ache, which would radiate to the ear during swallowing. The GP noticed an irritated throat and sent her to the local hospital for further evaluation. His referral letter described odynophagia and he asked them to exclude pathology. The specialist diagnosed tongue cancer and sent her to the head and neck oncology centre. His referral letter documented the physical examination of the head and neck region. At the oncology centre polyclinic visit she had already lost $11 \mathrm{~kg}$ of her initial body weight (12\%) in 6 months (formerly $89 \mathrm{~kg}$, height $1.72 \mathrm{~m}$ [BMI $\left.\left.30.1 \mathrm{~kg} / \mathrm{m}^{2}\right]\right)$. She received treatment through surgery and radiotherapy (tumour stage T2NOMO) and received energy (protein) supplements. Her weight stabilised.

\section{DISCUSSION}

Both patients are illustrative of the vulnerable nutritional balance in the chronically ill. The first patient lost weight due to multifactorial causes, triggered by an infection. The infection caused anorexia, resulting in weight loss. A diminished nutritional status, in turn, impaired her immune system, which led to the vicious circle of further weight loss and decline in resistance. ${ }^{8}$ The second patient lost more than $10 \%$ of her premorbid weight due to cancer, which is known to be an unfavourable prognostic sign. ${ }^{9}$ Early intervention can only be realised by improving case finding with regular weight measurements. In these cases, nutrition- related complaints were discussed between the patient, GP, and/or specialist, but no objective measurement of (change in) body weight had been pursued, nor had body weight been reported in referral letters. This points to a lack of proactive orientation towards cachexia, as illustrated in the present study (CAM Van Wayenburg et al, unpublished data, 2008).

In order to include the prevention of weight loss in the care for patients at risk, it is essential to promote regular measurements of body weight before significant weight loss occurs, and to report them in case of referral or transfer of care. For cancer, COPD, and chronic heart failure, patients' weight should be monitored regularly from the time of (possible) diagnosis, since early intervention in the case of cachexia may contribute to an enhanced quality of life..$^{3,4}$

\section{Consent}

Both patients gave their consent for publication of the case histories.

\section{Funding body}

Not applicable

\section{Ethics committee}

Not applicable

\section{Competing interests}

The authors have stated that there are none

\section{Acknowledgements}

We thank the participants, GPs, and specialists for their responses and participation.

\section{Discuss this article}

Contribute and read comments about this article on the Discussion Forum: http://www.rcgp.org.uk/bjgp-discuss

\section{REFERENCES}

1. Tan BH, Fearon KC. Cachexia: prevalence and impact in medicine. Curr Opin Clin Nutr Metab Care 2008; 11(4): 400-407.

2. Inui A. Cancer anorexia-cachexia syndrome: current issues in research and management. CA Cancer J Clin 2002; 52(2): 72-91.

3. Fearon KC. Cancer cachexia: developing multimodal therapy for a multidimensional problem. Eur J Cancer 2008; 44(8): 1124-1132.

4. Isenring EA, Capra S, Bauer JD. Nutrition intervention is beneficial in oncology outpatients receiving radiotherapy to the gastrointestinal or head and neck area. Br J Cancer 2004; 91(3): 447-452.

5. Ravasco P, Monteiro-Grillo I, Vidal PM, et al. Cancer: disease and nutrition are key determinants of patients' quality of life. Support Care Cancer 2004; 12(4): 246-252.

6. Soeters PB, Reijven PL, van Bokhorst-de van der Schueren MA, et al. A rational approach to nutritional assessment. Clin Nutr 2008; 27(5): 706-716.

7. Van den Berg MGA, Rasmussen-Conrad EL, Gwasara GM, et al. A prospective study on weight loss and energy intake in patients with head and neck cancer, during diagnosis, treatment and revalidation. Clin Nutr 2006; 25(5): 765-772.

8. Field CJ, Johnson IR, Schley PD. Nutrients and their role in host resistance to infection. J Leukoc Biol 2002; 71(1): 16-32.

9. Couch M, Lai V, Cannon T, et al. Cancer cachexia syndrome in head and neck cancer patients: part I. Diagnosis, impact on quality of life and survival, and treatment. Head Neck 2007; 29(4): 401-411. 